\title{
Low Intake of Vegetables and Fruits and Risk of Colorectal Cancer: The Japan Collaborative Cohort Study
}

\author{
Norihiro Aoyama ${ }^{1}$, Miyuki Kawado ${ }^{1}$, Hiroya Yamada ${ }^{1}$, Shuji Hashimoto ${ }^{1}$, Koji Suzuki ${ }^{2}$, Kenji Wakai ${ }^{3}$, \\ Sadao Suzuki ${ }^{4}$, Yoshiyuki Watanabe ${ }^{5}$, and Akiko Tamakoshi ${ }^{6}$, for the JACC Study Group \\ ${ }^{1}$ Department of Hygiene, Fujita Health University School of Medicine, Toyoake, Aichi, Japan \\ ${ }^{2}$ Department of Public Health, Fujita Health University School of Health Sciences, Toyoake, Aichi, Japan \\ ${ }^{3}$ Department of Preventive Medicine, Nagoya University Graduate School of Medicine, Nagoya, Japan \\ ${ }^{4}$ Department of Public Health, Nagoya City University Graduate School of Medical Sciences, Nagoya, Japan \\ ${ }^{5}$ Department of Epidemiology for Community Health and Medicine, Kyoto Prefectural University of Medicine Graduate School of Medical Science, \\ Kyoto, Japan \\ ${ }^{6}$ Department of Public Health, Hokkaido University Graduate School of Medicine, Sapporo, Japan
}

Received December 26, 2013; accepted March 16, 2014; released online May 24, 2014

Copyright (C) 2014 Norihiro Aoyama et al. This is an open access article distributed under the terms of Creative Commons Attribution License, which permits unrestricted use, distribution, and reproduction in any medium, provided the original author and source are credited.

\begin{abstract}
Background: The evidence for an association between low intake of vegetables and fruits and increased colorectal cancer risk is inconclusive. Evaluating the colorectal cancer risk associated with continued low intake is important. Methods: We used data of 45516 and 14549 subjects aged 40-79 years obtained in the baseline and interim surveys, respectively, from the Japan Collaborative Cohort Study for Evaluation of Cancer Risk (JACC Study). The intake frequency of vegetables and fruits as assessed by a self-administered questionnaire was classified into tertiles of low, middle, and high groups, and the low group was subdivided into 2 equal groups (lower low and higher low groups). Colorectal cancer incidence determined from follow-up was used. Cox's proportional hazard model was employed to estimate the hazard ratios (HRs) and 95\% confidence intervals (CIs), adjusting for covariates.

Results: During 598605 person-years of subject follow-up after baseline, we identified 806 colorectal cancer cases. HRs for the lower low versus the middle and high intake frequencies of vegetables and fruits at baseline were 0.95 (95\% CI 0.77-1.16) and 1.08 (95\% CI 0.90-1.29), respectively. During 125980 person-years of subject follow-up after the interim survey, 197 colorectal cancer cases were identified. HRs for the low versus middle and high intake frequencies of vegetables and fruits in both baseline and interim surveys were 0.91 (95\% CI 0.61-1.37) and 0.87 (95\% CI 0.59-1.27), respectively.
\end{abstract}

Conclusions: Our results suggest that low intake and continued low intake of vegetables and fruits are not strongly associated with colorectal cancer risk.

Key words: colorectal cancer; vegetables; fruits; food intake; epidemiology

\section{INTRODUCTION}

The association between vegetable and fruit intake and colorectal cancer risk has been investigated by many epidemiologic studies. ${ }^{1-9}$ Recent cohort studies have reported no effect or a weak protective association. ${ }^{5-9} \mathrm{~A}$ 2007 report from the World Cancer Research Fund and the American Institute for Cancer Research concluded that there was limited suggestive evidence for reduction in colorectal cancer risk by fruits and non-starchy vegetables. ${ }^{10}$ The update project report in 2011 stated that recent evidence was consistent with the previous conclusion. ${ }^{11}$ However, those reports on vegetable and fruit intake and colorectal cancer risk were based on review of the results from cohort studies mainly in Europe and the United States, with few studies conducted in Asia (including Japan)., ${ }^{4,8}$

Research on the association between vegetable and fruit intake and colorectal cancer risk is still inconclusive, and further studies are warranted. ${ }^{11-13}$ The hypothesis that low intake of vegetables and fruits could increase colorectal cancer risk has been proposed but has not been sufficiently tested. ${ }^{2,6,12}$ In most cohort studies, the intakes of vegetables and fruits were obtained only at baseline and were used for estimating the colorectal cancer incidence risk during the 
period of long-term follow-up. ${ }^{12,14}$ Because dietary habits could have changed during the period of follow-up, the data on food intake at baseline might not sufficiently reflect longterm exposure. ${ }^{15}$ We think that evaluating the colorectal cancer risk associated with continued low intake of vegetables and fruits using repeated measurements data for intake of vegetables and fruits is important. The Japan Collaborative Cohort Study for Evaluation of Cancer Risk (JACC Study) is a large-scale population-based cohort study in which the baseline and interim surveys included questionnaires assessing intake frequency of vegetables and fruits. ${ }^{16}$

We examined the association between vegetable and fruit intakes and the risk of colorectal cancer by analyzing the data from the baseline and interim surveys and the follow-up in the JACC Study. The focus of our analysis was to evaluate the colorectal cancer risk for participants with low intake of vegetables and fruits at baseline and continued low intake in the baseline and interim surveys.

\section{METHODS}

\section{The JACC Study}

The JACC Study aims to confirm the associations between cancer risk and lifestyle and living conditions. ${ }^{16}$ The baseline survey was conducted in 45 areas from 1988 to 1990, and 110585 Japanese adults aged 40-79 completed a selfadministered questionnaire. The interim survey was conducted in 31 areas about 5 years after the baseline survey, and 46650 participants completed the questionnaire. The questionnaires of the baseline and interim surveys included the same questions about intake frequency of vegetables and fruits.

Of 110585 participants at baseline, subjects for the present analysis were restricted to 65042 participants who lived in 24 areas where information on cancer incidence was available. ${ }^{16}$

The study protocol was approved by the Ethical Research Committee of Nagoya University School of Medicine.

\section{Subjects}

We analyzed colorectal cancer risk for intake frequency of vegetables and fruits at baseline using the data from the baseline survey. Out of 65042 participants with information on cancer incidence at baseline, 3290 with a cancer history at baseline and 16236 with no answers on intake frequency of vegetables and fruits in the baseline questionnaire were excluded. Thus, 45516 subjects (18946 males and 26570 females) were left for analysis of colorectal cancer risk for intake frequency at baseline.

We performed another analysis of colorectal cancer risk associated with change in intake frequency of vegetables and fruits using the data of baseline and interim surveys. Because the interim survey was not conducted in 14 study areas, and the target of the interim survey included only some of the participants who completed the baseline survey, ${ }^{15,16}$ out of 45516 subjects for analysis of intake frequency at baseline, we excluded 5576 who lived outside the study areas in the interim survey, 24705 who had no data on intake frequency of vegetables and fruits in the interim survey, 300 subjects who had a cancer history between the baseline and interim survey, and 386 who had no information on cancer incidence after the interim survey. Thus, 14549 subjects (5548 males and 9001 females) were left for analysis of colorectal cancer risk associated with change in intake frequency of vegetables and fruits.

\section{Vegetable and fruit intake and other factors}

The questionnaire administered during the baseline survey covered lifestyle factors, including diet, smoking and drinking, and physical activity, as well as medical history, education, family history of cancer, height, and weight. ${ }^{16}$ The questionnaire administered during the interim survey included diet, smoking and drinking, medical history, and family history of cancer, but not physical activity, education, height, or weight.

We inquired about average intake frequency in the past year for 5 vegetable items (spinach, carrot and pumpkin, tomato, cabbage and lettuce, and Chinese cabbage) and 2 fruit items (orange and other fruits) in baseline and interim surveys. ${ }^{17,18}$ We used five response categories and assigned numerical scores to their categories: 0 for almost never, 0.5 for $1-2$ times per month, 1.5 for 1-2 times per week, 3.5 for 3-4 times per week, and 6 for almost every day. Scores were averaged over items of vegetables and fruits.

We classified intake frequency of vegetables into tertile groups according to scores: $<1.9$ (low), 1.9-3.0 (middle), and $\geq 3.1$ (high) for males, and $<2.3$ (low), 2.3-3.5 (middle), and $\geq 3.6$ (high) for females. The group of low food frequency was subdivided into 2 equal groups: $<1.3$ (lower low) and 1.3-1.8 (higher low) for males, and $<1.6$ (lower low) and 1.6-2.2 (higher low) for females. Also, we classified intake frequency of fruits into tertile groups according to scores: $<1.8$ (low), 1.8-3.7 (middle), and $\geq 3.8$ (high) for males, and $<3.3$ (low), 3.3-4.8 (middle), and $\geq 4.9$ (high) for females. The group of low food frequency was subdivided into 2 equal groups: $<1.0$ (lower low) and 1.0-1.7 (higher low) for males, and $<1.5$ (lower low) and 1.5-3.2 (higher low) for females.

For the analysis of colorectal cancer risk associated with change in food frequency, we classified these food frequency groups in the baseline and interim surveys into combination groups. For example, subjects in the low food frequency group in the baseline survey and middle food frequency group in the interim survey was denoted as "low to middle".

\section{Follow-up}

In the JACC Study, population registries in the municipalities were used for follow-up of the subjects. ${ }^{16}$ In most areas, follow-up was completed at the end of 2009; however, it was stopped at the end of 1999 in 4 areas, at the end of 2003 in another 4 areas, and at the end of 2008 in 2 areas. We 
discontinued follow-up of those who had moved out of their area after the baseline survey.

We identified the incidence of cancer by linkage with the records of population-based cancer registries, supplemented by a systematic review of death certificates. ${ }^{19}$ In 4 out of 24 areas, population-based cancer registries were not available, so hospital-based cancer registries or inpatient records of hospitals treating cancer patients were used. The mortalityto-incidence ratio of cancer from the follow-up data, which served as an index for completeness of identification of cancer incidence, was reported as 0.43 in males and 0.38 in females, but the percentage of cases identified from a death certificate only (DCO\%) was not. ${ }^{19}$

We defined colon cancer as C18 and rectum cancer as C20 according to the 10th Revision of the International Statistical Classification of Diseases and the Related Health Problems.

\section{Statistical analysis}

For the analysis of colorectal cancer risk associated with intake frequency of vegetables and fruits at baseline, we used the baseline survey data and the follow-up data from the response of baseline survey (the registration of JACC study) in 1988-1990 to the end of the follow-up in 2009. The hazard ratios (HRs) and 95\% confidence intervals (CIs) for colorectal cancer according to intake frequency of vegetables and fruits at baseline (the HRs for lower low, and higher low food frequencies versus the middle and high food frequencies) were estimated using Cox's proportional hazard models. For the analysis of colorectal cancer risk for change in intake frequency of vegetables and fruits, we used the data from baseline and interim surveys and the follow-up data from the responses to the interim survey to the end of the follow-up in 2009. The HRs and $95 \%$ CIs for colorectal cancers according to change in intake frequency of vegetables and fruits (the HRs for low to low, low to middle and high, and middle and high to low food frequencies versus middle and high to middle and high food frequency) were estimated.

For the analysis of colorectal cancer risk for intake frequency of vegetables and fruits at baseline, we adjusted for the following potential confounding factors at baseline: sex, age (40-44 years, 45-49, 50-54, 55-59, 60-64, 65-69, 70-74, or 75-79), district (Hokkaido and Tohoku, Kanto, Tokai, Kinki, Chugoku, or Kyushu), smoking (current smoker of 20 or more cigarettes per day, current smoker of 1-19 cigarettes per day or unknown numbers, former smoker, or nonsmoker), drinking (current drinker with everyday drinking, current drinker without everyday drinking, former drinker, or nondrinker), intake frequency of beef and pork (tertile groups according to scores: $<2.0,2.0-3.4$, or $\geq 3.5$ times per week), family history of colorectal cancer in parents and/or siblings (yes or no), education (attended school until $\geq 18$ years, or $<18$ years), body mass index calculated as weight $(\mathrm{kg}) /$ height $(\mathrm{m})^{2}(<18.5,18.5-24.9$, or $\geq 25.0)$, and walking time $(\geq 30 \mathrm{~min} /$ day or $<30)$. For the analysis of colorectal cancer risk for change in intake frequency of vegetables and fruits, we adjusted for sex, age, district, smoking, drinking, intake frequency of beef and pork, and family history of colorectal cancer in parents and/or siblings at the interim survey, and education, body mass index, and walking time at baseline. Missing values for each covariate were treated as an additional category in the variables and were included in the Cox's proportional hazard model. All analyses were performed using the SAS statistical package, version 9.3 (SAS, Institute, Cary, NC, USA).

\section{RESULTS}

Table 1 shows the characteristics of subjects for analysis of colorectal cancer risk associated with intake frequency of vegetables and fruits at baseline. The average age at baseline was 56.7 years. The proportions of lower low intake frequency of vegetables and fruits at baseline were $15.9 \%$ and $19.1 \%$, respectively. The proportion of current smokers was $52.7 \%$ in males and $5.1 \%$ in females. The proportion of body mass index of $\geq 25 \mathrm{~kg} / \mathrm{m}^{2}$ was $20.8 \%$.

Table 2 shows the characteristics of subjects for analysis of colorectal cancer risk associated with change in intake frequency of vegetables and fruits. The average age at the interim survey was 60.8 years. The proportions of low to low intake frequency of vegetables and fruits were $16.8 \%$ and $21.9 \%$, respectively. The proportion of current smokers was $43.4 \%$ in males and $3.6 \%$ in females. The proportion of body mass index of $25 \mathrm{~kg} / \mathrm{m}^{2}$ and over was $18.8 \%$.

During 598605 person-years of subject follow-up for analysis of colorectal cancer risk associated with intake frequency of vegetables and fruits at baseline, there were 552 cases of colon cancer (299 males and 253 females) and 254 cases of rectal cancer (168 males and 86 females). The DCO $\%$ in colorectal cancer cases was $8.4 \%$. The mortality-toincidence ratio was 0.35 . During 125980 person-years of subject follow-up for analysis of colorectal cancer risk associated with change in intake frequency of vegetables and fruits, there were 137 cases of colon cancer ( 76 males and 61 females) and 60 cases of rectal cancer (43 males and 17 females). The DCO \% in colorectal cancer cases was $6.6 \%$. The mortality-to-incidence ratio was 0.40 .

Table 3 shows the HR and 95\% CI for colorectal cancer incidence for analysis of intake frequency of vegetables and fruits at baseline, adjusted for sex, age, district, smoking, drinking, intake frequency of beef and pork, family history of colorectal cancer, education, body mass index, and walking time. We found no significant association between the low intake frequency of vegetables or fruits and colorectal cancer incidence. HR of colorectal cancer incidence for the lower low versus the middle and high intake frequencies of vegetables and fruits at baseline was 0.95 (95\% CI $0.77-1.16)$ and 1.08 (95\% CI 0.90-1.29), respectively. HRs of colon or rectal cancer incidence for the lower low versus the middle and high 
Table 1. Characteristics of subjects for analysis of colorectal cancer incidence for food frequency at baseline

\begin{tabular}{|c|c|c|c|}
\hline Characteristics at baseline & Males & Females & All \\
\hline Number of subjects & 18946 & 26570 & 45516 \\
\hline \multicolumn{4}{|l|}{ Age (years) } \\
\hline mean, standard deviation & $56.5,10.2$ & $56.9,10.0$ & $56.7,10.1$ \\
\hline \multicolumn{4}{|l|}{ Distinct (\%) } \\
\hline Hokkaido \& Tohoku & 8.5 & 8.9 & 8.8 \\
\hline Kanto & 22.2 & 34.3 & 29.3 \\
\hline Chubu & 9.5 & 9.8 & 9.7 \\
\hline Kinki & 49.5 & 38.9 & 43.3 \\
\hline Chugoku \& Kyushu & 10.3 & 8.1 & 9.1 \\
\hline \multicolumn{4}{|l|}{ Intake frequency ${ }^{\mathrm{a}}$} \\
\hline \multicolumn{4}{|l|}{ Vegetables (\%) } \\
\hline Lower low & 15.4 & 16.2 & 15.9 \\
\hline Higher low & 17.2 & 15.2 & 16.0 \\
\hline Middle & 31.9 & 36.1 & 34.4 \\
\hline High & 35.4 & 32.5 & 33.7 \\
\hline \multicolumn{4}{|l|}{ Fruits (\%) } \\
\hline Lower low & 21.5 & 17.4 & 19.1 \\
\hline Higher low & 11.9 & 14.7 & 13.5 \\
\hline Middle & 30.2 & 38.8 & 35.2 \\
\hline High & 36.4 & 29.2 & 32.2 \\
\hline \multicolumn{4}{|l|}{ Other characteristics } \\
\hline \multicolumn{4}{|l|}{ Smoking (\%) } \\
\hline $\begin{array}{l}\text { Current smoker of } 20 \text { or } \\
\text { more cigarettes per day }\end{array}$ & 34.9 & 1.4 & 15.7 \\
\hline Current smoker of $1-19$ & & & \\
\hline $\begin{array}{l}\text { cigarettes per day or } \\
\text { unknown numbers }\end{array}$ & 17.8 & 3.7 & 9.7 \\
\hline Former smoker & 26.3 & 1.5 & 12.1 \\
\hline Nonsmoker & 20.9 & 93.4 & 62.5 \\
\hline \multicolumn{4}{|l|}{ Drinking (\%) } \\
\hline $\begin{array}{l}\text { Current drinker with } \\
\text { everyday drinking }\end{array}$ & 52.4 & 5.5 & 25.1 \\
\hline $\begin{array}{l}\text { Current drinker without } \\
\text { everyday drinking }\end{array}$ & 23.3 & 18.4 & 20.5 \\
\hline Former drinker & 6.2 & 1.8 & 3.6 \\
\hline Nondrinker & 18.1 & 74.4 & 50.9 \\
\hline \multicolumn{4}{|c|}{ Intake frequency of beef and pork (\%) } \\
\hline$<2.0$ times per week & 37.4 & 36.3 & 36.8 \\
\hline 2.0-3.4 times per week & 25.4 & 27.0 & 26.3 \\
\hline$\geq 3.5$ times per week & 37.2 & 36.7 & 36.9 \\
\hline \multicolumn{4}{|c|}{ Family history of colorectal cancer (\%) } \\
\hline Yes & 2.4 & 2.8 & 2.6 \\
\hline No & 97.6 & 97.2 & 97.4 \\
\hline \multicolumn{4}{|l|}{ Education (\%) } \\
\hline \multicolumn{4}{|l|}{ Attended school until } \\
\hline$\geq 18$ years & 20.7 & 11.3 & 15.2 \\
\hline$<18$ years & 79.3 & 88.7 & 84.8 \\
\hline \multicolumn{4}{|l|}{ Body mass index (\%) } \\
\hline$<18.5 \mathrm{~kg} / \mathrm{m}^{2}$ & 5.1 & 6.1 & 5.7 \\
\hline $18.5-24.9 \mathrm{~kg} / \mathrm{m}^{2}$ & 76.1 & 71.7 & 73.5 \\
\hline$\geq 25.0 \mathrm{~kg} / \mathrm{m}^{2}$ & 18.9 & 22.1 & 20.8 \\
\hline \multicolumn{4}{|l|}{ Walking time (\%) } \\
\hline$\geq 30 \mathrm{~min} /$ day & 68.5 & 71.7 & 70.3 \\
\hline$<30 \mathrm{~min} /$ day & 31.5 & 28.3 & 29.7 \\
\hline
\end{tabular}

antake frequency of vegetables was grouped according to scores: $<1.3$ (lower low), 1.3-1.8 (higher low), 1.9-3.0 (middle) and $\geq 3.1$ (high) for males, and <1.6 (lower low), 1.6-2.2 (higher low), 2.3-3.5 (middle) and $\geq 3.6$ (high) for females. Intake frequency of fruits was grouped: $<1.0$ (lower low), 1.0-1.7 (higher low), 1.8-3.7 (middle) and $\geq 3.8$ (high) for males, and <1.5 (lower low), 1.5-3.2 (higher low), 3.3-4.8 (middle) and $\geq 4.9$ (high) for females. Intake frequency scores were averaged over items in vegetables, fruits, and beef and pork.

intake frequencies of vegetables or fruits at baseline in males or females ranged from 0.59 to 1.32 .

Table 4 shows the HRs and $95 \%$ CIs for colorectal cancer incidence for analysis of change in intake frequency of vegetables and fruits, adjusted for sex, age, district, smoking, drinking, intake frequency of beef and pork, family history of colorectal cancer, education, body mass index, and walking
Table 2. Characteristics of subjects for analysis of colorectal cancer incidence for change in food frequency

\begin{tabular}{|c|c|c|c|}
\hline Characteristics at interim survey & Males & Females & All \\
\hline Number of subjects & 5548 & 9001 & 14549 \\
\hline \multicolumn{4}{|l|}{ Age (years) } \\
\hline mean, standard deviation & $61.1,9.4$ & $60.6,9.3$ & $60.8,9.3$ \\
\hline \multicolumn{4}{|l|}{ Distinct (\%) } \\
\hline Hokkaido \& Tohoku & 2.0 & 1.9 & 1.9 \\
\hline Kanto & 40.5 & 51.3 & 47.2 \\
\hline Chubu & 5.9 & 4.0 & 4.7 \\
\hline Kinki & 39.1 & 33.5 & 35.6 \\
\hline Chugoku \& Kyushu & 12.6 & 9.3 & 10.5 \\
\hline \multicolumn{4}{|l|}{ Intake frequency ${ }^{a}$} \\
\hline \multicolumn{4}{|l|}{ Vegetables (\%) } \\
\hline Low to low & 17.6 & 16.3 & 16.8 \\
\hline Low to middle & 9.6 & 10.9 & 10.4 \\
\hline Low to high & 4.6 & 3.7 & 4.0 \\
\hline Middle to low & 9.6 & 9.8 & 9.8 \\
\hline Middle to middle & 13.8 & 18.2 & 16.5 \\
\hline Middle to high & 10.0 & 9.7 & 9.8 \\
\hline High to low & 5.6 & 3.6 & 4.4 \\
\hline High to middle & 11.1 & 11.1 & 11.1 \\
\hline High to high & 18.0 & 16.7 & 17.2 \\
\hline \multicolumn{4}{|l|}{ Fruits (\%) } \\
\hline Low to low & 22.5 & 21.5 & 21.9 \\
\hline Low to middle & 9.7 & 8.4 & 8.9 \\
\hline Low to high & 3.5 & 1.8 & 2.5 \\
\hline Middle to low & 11.8 & 13.8 & 13.1 \\
\hline Middle to middle & 12.0 & 19.1 & 16.4 \\
\hline Middle to high & 7.1 & 6.4 & 6.7 \\
\hline High to low & 5.9 & 4.6 & 5.1 \\
\hline High to middle & 10.1 & 12.8 & 11.8 \\
\hline High to high & 17.4 & 11.5 & 13.8 \\
\hline \multicolumn{4}{|l|}{ Other characteristics } \\
\hline \multicolumn{4}{|l|}{ Smoking (\%) } \\
\hline $\begin{array}{l}\text { Current smoker of } 20 \text { or } \\
\text { more cigarettes per day }\end{array}$ & 28.3 & 1.0 & 11.7 \\
\hline $\begin{array}{l}\text { Current smoker of } 1-19 \\
\text { cigarettes per day or } \\
\text { unknown numbers }\end{array}$ & 15.1 & 2.5 & 7.5 \\
\hline Former smoker & 31.3 & 1.4 & 13.2 \\
\hline Never smoked & 25.2 & 95.1 & 67.6 \\
\hline \multicolumn{4}{|l|}{ Drinking (\%) } \\
\hline $\begin{array}{l}\text { Current drinker with } \\
\text { everyday drinking }\end{array}$ & 55.6 & 6.5 & 25.6 \\
\hline $\begin{array}{l}\text { Current drinker without } \\
\text { everyday drinking }\end{array}$ & 19.5 & 16.3 & 17.6 \\
\hline Former drinker & 4.4 & 1.3 & 2.5 \\
\hline Never drinked & 20.5 & 75.9 & 54.3 \\
\hline \multicolumn{4}{|c|}{ Intake frequency of beef and pork (\%) } \\
\hline$<2.0$ times per week & 34.3 & 31.0 & 32.3 \\
\hline 2.0-3.4 times per week & 17.8 & 20.4 & 19.4 \\
\hline$\geq 3.5$ times per week & 47.8 & 48.6 & 48.3 \\
\hline \multicolumn{4}{|c|}{ Family history of colorectal cancer (\%) } \\
\hline Yes & 7.4 & 7.6 & 7.5 \\
\hline No & 92.6 & 92.4 & 92.5 \\
\hline \multicolumn{4}{|l|}{ Education $(\%)^{\mathrm{b}}$} \\
\hline \multicolumn{4}{|l|}{ Attended school until } \\
\hline$\geq 18$ years & 22.4 & 11.8 & 15.8 \\
\hline$<18$ years & 77.6 & 88.2 & 84.2 \\
\hline \multicolumn{4}{|l|}{ Body mass index $(\%)^{\mathrm{b}}$} \\
\hline$<18.5 \mathrm{~kg} / \mathrm{m}^{2}$ & 4.7 & 5.8 & 5.4 \\
\hline $18.5-24.9 \mathrm{~kg} / \mathrm{m}^{2}$ & 78.1 & 74.5 & 75.9 \\
\hline$\geq 25.0 \mathrm{~kg} / \mathrm{m}^{2}$ & 17.2 & 19.7 & 18.8 \\
\hline \multicolumn{4}{|l|}{ Walking time $(\%)^{\mathrm{b}}$} \\
\hline$\geq 30 \mathrm{~min} /$ day & 71.4 & 73.8 & 72.9 \\
\hline$<30 \mathrm{~min} /$ day & 28.6 & 26.2 & 27.1 \\
\hline
\end{tabular}

antake frequency of vegetables was grouped according to scores: $<1.9$ (low), 1.9-3.0 (middle) and $\geq 3.1$ (high) for males, and <2.3 (low), 2.3-3.5 (middle) and $\geq 3.6$ (high) for females. Intake frequency of fruits was grouped: $<1.8$ (low), 1.8-3.7 (middle) and $\geq 3.8$ (high) for males, and $<3.3$ (lower low), 3.3-4.8 (middle) and $\geq 4.9$ (high) for females. Intake frequency scores were averaged over items of vegetables, fruits, and beef and pork. These food frequency groups in the baseline and interim surveys were classified into combination groups. For example, participants in the low food frequency group in the baseline survey and middle food frequency group in the interim survey were denoted as "low to middle".

bData were from the baseline survey. 
Table 3. Hazard ratio (HR) and $95 \%$ confidence interval $(\mathrm{Cl})$ for colorectal cancer incidence for analysis of food frequency at baseline

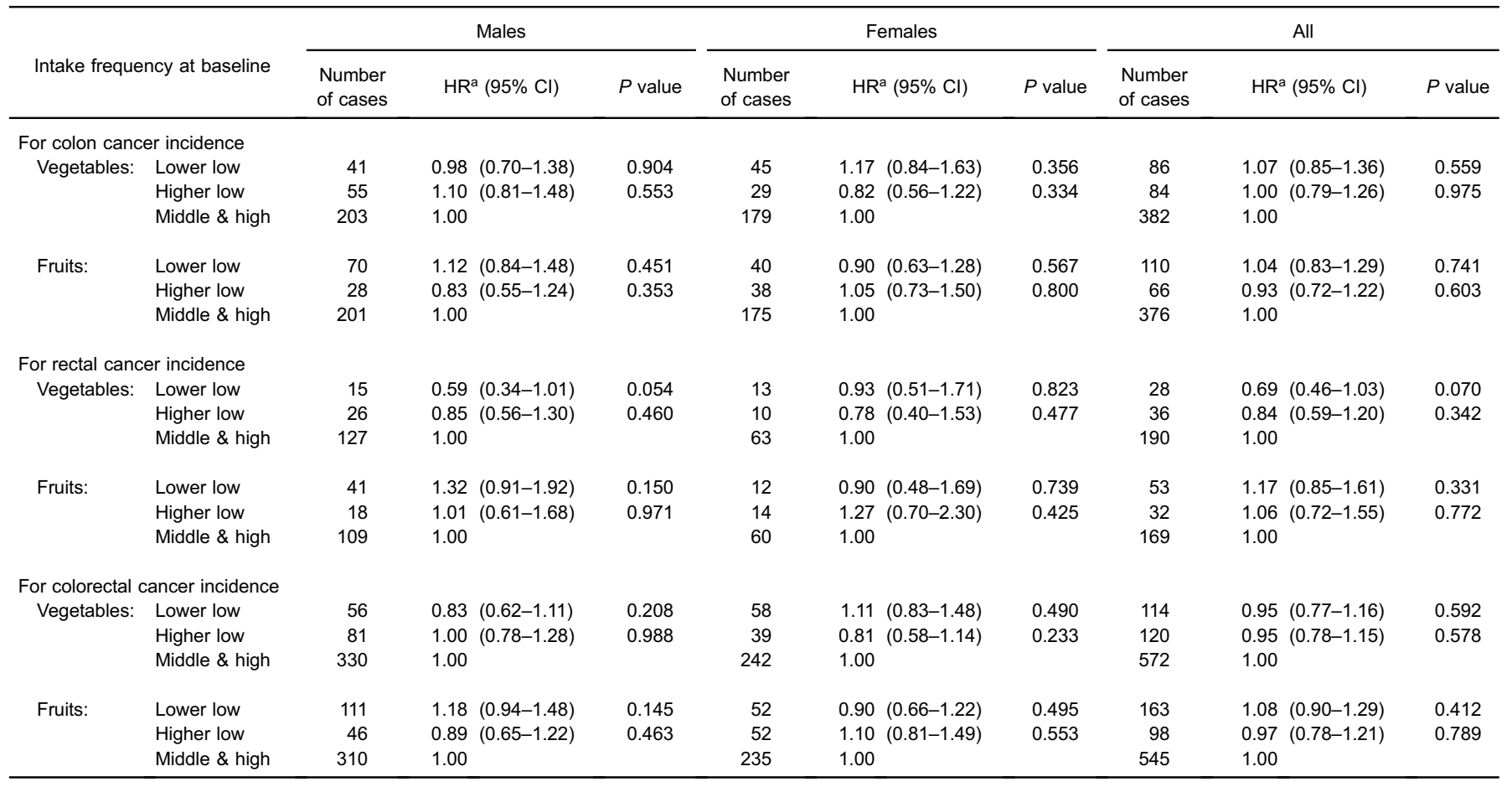

aHazard ratio was adjusted for sex, age, district, smoking, drinking, intake frequency of beef and pork, family history of colorectal cancer, education, body mass index, and walking time at baseline.

Table 4. Hazard ratio (HR) and $95 \%$ confidence interval (CI) for colorectal cancer incidence for analysis of change in food frequency

\begin{tabular}{|c|c|c|c|c|c|c|c|c|c|c|c|}
\hline \multirow{2}{*}{\multicolumn{2}{|c|}{ Change in intake frequency }} & \multicolumn{4}{|c|}{ Males } & \multicolumn{3}{|c|}{ Females } & \multicolumn{3}{|c|}{ All } \\
\hline & & $\begin{array}{l}\text { Number } \\
\text { of cases }\end{array}$ & & $\mathrm{R}^{\mathrm{a}}(95 \% \mathrm{Cl})$ & $\begin{array}{c}P \\
\text { value }\end{array}$ & $\begin{array}{l}\text { Number } \\
\text { of cases }\end{array}$ & $\mathrm{HR}^{\mathrm{a}}(95 \% \mathrm{Cl})$ & $\begin{array}{c}P \\
\text { value }\end{array}$ & $\begin{array}{l}\text { Number } \\
\text { of cases }\end{array}$ & $\mathrm{HR}^{\mathrm{a}}(95 \% \mathrm{Cl})$ & $\begin{array}{c}P \\
\text { value }\end{array}$ \\
\hline \multicolumn{12}{|c|}{ For colon cancer incidence } \\
\hline \multirow[t]{4}{*}{ Vegetables: } & Low to low & 16 & 1.21 & $1(0.67-2.20)$ & 0.533 & 6 & $0.59(0.25-1.42)$ & 0.241 & 22 & $0.92(0.57-1.50)$ & 0.749 \\
\hline & Low to middle \& high & 10 & 0.88 & $8(0.44-1.77)$ & 0.720 & 5 & $0.48(0.19-1.21)$ & 0.118 & 15 & 0.68 (0.39-1.19) & 0.174 \\
\hline & Middle \& high to low & 10 & 0.88 & $8(0.44-1.78)$ & 0.727 & 8 & $0.88(0.41-1.90)$ & 0.753 & 18 & $0.86(0.51-1.44)$ & 0.564 \\
\hline & Middle \& high to middle \& high & 40 & 1.00 & & & 42 & 1.00 & & 82 & 1.00 & \\
\hline \multirow[t]{4}{*}{ Fruits: } & Low to low & 17 & 0.96 & $6(0.51-1.82)$ & 0.901 & 15 & $1.17(0.60-2.28)$ & 0.644 & 32 & $1.03(0.65-1.63)$ & 0.892 \\
\hline & Low to middle \& high & 9 & 0.93 & $3(0.44-1.98)$ & 0.851 & 4 & $0.65(0.23-1.88)$ & 0.429 & 13 & $0.80(0.44-1.48)$ & 0.481 \\
\hline & Middle \& high to low & 19 & 1.47 & $7(0.81-2.66)$ & 0.204 & 14 & $1.27(0.66-2.46)$ & 0.474 & 33 & $1.37(0.89-2.13)$ & 0.155 \\
\hline & Middle \& high to middle \& high & 31 & 1.00 & & & 28 & 1.00 & & 59 & 1.00 & \\
\hline \multicolumn{12}{|c|}{ For rectal cancer incidence } \\
\hline \multirow[t]{4}{*}{ Vegetables: } & Low to low & 5 & 0.58 & $8(0.22-1.55)$ & 0.274 & 4 & $2.03(0.61-6.81)$ & 0.252 & 9 & $0.88(0.41-1.87)$ & 0.741 \\
\hline & Low to middle \& high & 6 & 0.77 & 7 (0.31-1.89) & 0.566 & 2 & $0.90(0.19-4.17)$ & 0.887 & 8 & $0.81(0.37-1.76)$ & 0.592 \\
\hline & Middle \& high to low & 6 & 0.73 & $3(0.30-1.80)$ & 0.497 & 1 & $0.60(0.08-4.80)$ & 0.630 & 7 & $0.70(0.31-1.59)$ & 0.394 \\
\hline & Middle $\&$ high to middle $\&$ high & 26 & 1.00 & & & 10 & 1.00 & & 36 & 1.00 & \\
\hline \multirow[t]{4}{*}{ Fruits: } & Low to low & 9 & 0.58 & $8(0.26-1.33)$ & 0.198 & 2 & $0.57(0.12-2.77)$ & 0.488 & 11 & $0.57(0.28-1.17)$ & 0.127 \\
\hline & Low to middle \& high & 3 & 0.35 & $5(0.11-1.18)$ & 0.091 & 1 & $0.39(0.05-3.06)$ & 0.367 & 4 & $0.37(0.13-1.05)$ & 0.063 \\
\hline & Middle \& high to low & 6 & 0.52 & $2(0.21-1.31)$ & 0.165 & 4 & $1.29(0.39-4.33)$ & 0.676 & 10 & 0.67 (0.33-1.38) & 0.279 \\
\hline & Middle $\&$ high to middle $\&$ high & 25 & 1.00 & & & 10 & 1.00 & & 35 & 1.00 & \\
\hline \multicolumn{12}{|c|}{ For colorectal cancer incidence } \\
\hline \multirow[t]{4}{*}{ Vegetables: } & Low to low & 21 & 0.96 & $6(0.58-1.60)$ & 0.885 & 10 & $0.83(0.42-1.67)$ & 0.607 & 31 & $0.91(0.61-1.37)$ & 0.650 \\
\hline & Low to middle \& high & 16 & 0.84 & $4(0.48-1.46)$ & 0.531 & 7 & $0.56(0.25-1.23)$ & 0.146 & 23 & $0.73(0.46-1.14)$ & 0.163 \\
\hline & Middle \& high to low & 16 & 0.83 & $3(0.48-1.44)$ & 0.507 & 9 & $0.83(0.41-1.69)$ & 0.602 & 25 & $0.81(0.53-1.26)$ & 0.355 \\
\hline & Middle \& high to middle \& high & 66 & 1.00 & & & 52 & 1.00 & & 118 & 1.00 & \\
\hline \multirow[t]{4}{*}{ Fruits: } & Low to low & 26 & 0.80 & $0(0.49-1.32)$ & 0.388 & 17 & $1.02(0.56-1.87)$ & 0.939 & 43 & $0.87(0.59-1.27)$ & 0.468 \\
\hline & Low to middle \& high & 12 & 0.66 & $6(0.35-1.25)$ & 0.203 & 5 & $0.58(0.23-1.48)$ & 0.252 & 17 & 0.64 (0.38-1.07) & 0.090 \\
\hline & Middle \& high to low & 25 & 1.04 & $4(0.64-1.70)$ & 0.862 & 18 & $1.25(0.70-2.23)$ & 0.446 & 43 & $1.12(0.77-1.62)$ & 0.554 \\
\hline & Middle \& high to middle \& high & 56 & 1.00 & & & 38 & 1.00 & & 94 & 1.00 & \\
\hline
\end{tabular}

aHazard ratio was adjusted for sex, age, district, smoking, drinking, intake frequency of beef and pork and family history of colorectal cancer at the interim survey, and education, body mass index, and walking time at baseline. 
time. We found no significant association between the low to low intake frequency of vegetables or fruits and colorectal cancer incidence. HRs of colorectal cancer incidence for the low to low versus middle and high to middle and high intake frequency of vegetables and fruits were 0.91 (95\% CI $0.61-1.37$ ) and 0.87 (95\% CI 0.59-1.27), respectively. HRs of colon or rectal cancer incidence for the low to low versus middle and high to middle and high intake frequency of vegetables or fruits in males or females ranged from 0.57 to 2.03 .

\section{DISCUSSION}

Analysis of data from a population-based cohort study in Japan (the JACC Study) showed no significant associations between the intake frequency of vegetables or fruits and colorectal cancer incidence. Many recent cohort studies in Europe and the United States have found no or a weak protective association between vegetable and fruit intakes and colorectal cancer incidence..$^{5,6,9,11}$ Our results are consistent with those of other cohort studies for Japanese inhabitants, showing no substantial protective associations. ${ }^{4,20}$

A focus of our analysis was to evaluate the colorectal cancer risk for having low intake of vegetables and fruits. We used the lower low intake frequency group (less than $20 \%$ of our subjects) as the low food intake category in our analysis. HRs for the lower low intake frequencies of vegetables and fruits at baseline was not significant at 0.95 and 1.08, respectively. It has been hypothesized that low vegetable and fruit consumption beyond a certain level leads to an increase in colorectal cancer risk, ${ }^{6,12,13}$ although the level is not clearly defined. ${ }^{12}$ Although the lower low intake frequency of vegetables and fruits in the present study might not be below the level described in the hypothesis, our results do not support the hypothesis.

Another focus of our analysis was to evaluate the colorectal cancer risk associated with continued low intake of vegetables and fruits. In most cohort studies on colorectal cancer risk, vegetable and fruit intakes have been measured only at baseline. ${ }^{12,14}$ Such data might lead to underestimation of the colorectal cancer risk associated with low vegetable and fruit intakes during the period of follow-up, because diets may change considerably over time. ${ }^{12,15}$ Although we found no significant increased risk of colorectal cancer in the low to low intake frequency group, it should be noted that our results were obtained through analysis partly considering the change in intake frequency of vegetables and fruits over time and therefore provide useful information for evaluating the colorectal cancer risk associated with vegetable and fruit intake.

Some problems and limitations in the present study warrant mention. We used the intake frequency of vegetables and fruits assessed by a self-administered questionnaire but did not obtain the actual vegetable and fruit intake. HRs of low intake of vegetables and fruits for colorectal cancer risk based on data of intake frequency in the present study may therefore not be entirely accurate. However, the questionnaire of food frequencies has been validated by referring to four 3-day weighed dietary records over a 1-year period as a standard and was found to be suitable for use in a large group of subjects. ${ }^{18}$ Most members of the low, middle, and high intake frequency groups in our analysis would be low, middle, and high in intake, respectively. Thus, based on the amounts of intake, HRs of low intake of vegetables and fruits for colorectal cancer risk should not substantially differ from our estimates.

For identification of cancer incidence in the JACC Study, population-based cancer registries were available in 20 areas, but hospital-based cancer registries or inpatient records of hospitals treating cancer patients were instead used in 4 areas. ${ }^{19}$ The completeness of identification for cancer incidence varies across study areas. In our two analyses, the $\mathrm{DCO} \%(8.4 \%$ and $6.6 \%)$ and mortality-to-incidence ratio ( 0.35 and 0.40$)$ for colorectal cancer were comparable to those from representative population-based cancer registries in Japan. $^{21}$

The analysis of colorectal cancer risk associated with intake frequency of vegetables and fruits at baseline based on 806 cases of colorectal cancer seemed to have considerable statistical power of significance. ${ }^{10}$ In contrast, only 197 cases of colorectal cancer were available for the analysis of changes in intake frequency of vegetables and fruits. Thus, the HRs for low to low frequency of vegetable and fruit intake would include considerable uncertainty. Further studies with sufficient statistical power to confirm these findings are therefore necessary. We adjusted for some covariates in the Cox's proportional hazard models, and although the covariates were similar to those from previous reports on the association between vegetable and fruit intake and colorectal cancer risk, possible residual confounding cannot be ruled out., ${ }^{4,20}$

In conclusion, our results suggested that low intake and continued low intake of vegetables and fruits were not strongly associated with colorectal cancer risk.

\section{ONLINE ONLY MATERIAL}

Abstract in Japanese.

\section{ACKNOWLEDGMENTS}

The authors sincerely express their appreciation to Dr. Kunio Aoki, Professor Emeritus, Nagoya University School of Medicine and the former chairman of the JACC Study; to Dr. Haruo Sugano, former director of the Cancer Institute, Tokyo, who greatly contributed to the initiation of the JACC Study; and to Dr. Yoshiyuki Ohno, Professor Emeritus, Nagoya University School of Medicine, who was the past chairman of the study. The authors also wish to thank Dr. Tomoyuki Kitagawa, Cancer Institute of the Japanese 
Foundation for Cancer Research and the former chairman of Grant-in-Aid for Scientific Research on the Priority Area of Cancer, and Dr. Kazuo Tajima, Mie University, the former chairman of Grant-in Aid for Scientific Research on the Priority Area of Cancer Epidemiology, for their full support of this study.

The JACC study was supported by Grants-in-Aid for Scientific Research from the Ministry of Education, Science, Sports and Culture of Japan (Monbusho), and Grants-in-Aid for Scientific Research on Priority Areas of Cancer, as well as Grants-in-Aid for Scientific Research on Priority Areas of Cancer Epidemiology from the Japanese Ministry of Education, Culture, Sports, Science and Technology (MonbuKagaku-sho) (Nos. 61010076, 62010074, 63010074, 1010068, 2151065, 3151064, 4151063, 5151069, 6279102, 11181101, 17015022, 18014011, 20014026 and 20390156).

Conflicts of interest: None declared.

\section{Members of JACC Study Group}

The present members of the JACC Study Group who coauthored this paper are: Dr. Akiko Tamakoshi (present chairperson of the study group), Hokkaido University Graduate School of Medicine; Drs. Mitsuru Mori \& Fumio Sakauchi, Sapporo Medical University School of Medicine; Dr. Yutaka Motohashi, Akita University School of Medicine; Dr. Ichiro Tsuji, Tohoku University Graduate School of Medicine; Dr. Yosikazu Nakamura, Jichi Medical School; Dr. Hiroyasu Iso, Osaka University School of Medicine; Dr. Haruo Mikami, Chiba Cancer Center; Dr. Michiko Kurosawa, Juntendo University School of Medicine; Dr. Yoshiharu Hoshiyama, Yokohama Soei University; Dr. Naohito Tanabe, University of Niigata Prefecture; Dr. Koji Tamakoshi, Nagoya University Graduate School of Health Science; Dr. Kenji Wakai, Nagoya University Graduate School of Medicine; Dr. Shinkan Tokudome, National Institute of Health and Nutrition; Dr. Koji Suzuki, Fujita Health University School of Health Sciences; Dr. Shuji Hashimoto, Fujita Health University School of Medicine; Dr. Shogo Kikuchi, Aichi Medical University School of Medicine; Dr. Yasuhiko Wada, Faculty of Nutrition, University of Kochi; Dr. Takashi Kawamura, Kyoto University Center for Student Health; Dr. Yoshiyuki Watanabe, Kyoto Prefectural University of Medicine Graduate School of Medical Science; Dr. Kotaro Ozasa, Radiation Effects Research Foundation; Dr. Tsuneharu Miki, Kyoto Prefectural University of Medicine Graduate School of Medical Science; Dr. Chigusa Date, School of Human Science and Environment, University of Hyogo; Dr. Kiyomi Sakata, Iwate Medical University; Dr. Yoichi Kurozawa, Tottori University Faculty of Medicine; Drs. Takesumi Yoshimura \& Yoshihisa Fujino, University of Occupational and Environmental Health; Dr. Akira Shibata, Kurume University; Dr. Naoyuki Okamoto, Kanagawa Cancer Center; and Dr. Hideo Shio, Moriyama Municipal Hospital.

\section{REFERENCES}

1. Terry P, Giovannucci E, Michels KB, Bergkvist L, Hansen H, Holmberg L, et al. Fruit, vegetables, dietary fiber, and risk of colorectal cancer. J Natl Cancer Inst. 2001;93:525-33.

2. McCullough ML, Robertson AS, Chao A, Jacobs EJ, Stampfer MJ, Jacobs DR, et al. A prospective study of whole grains, fruits, vegetables and colon cancer risk. Cancer Causes Control. 2003;14:959-70.

3. Wark PA, Weijenberg MP, van 't Veer P, van Wijhe G, Lüchtenborg M, van Muijen GN, et al. Fruits, vegetables, and hMLH1 protein-deficient and -proficient colon cancer: The Netherlands cohort study. Cancer Epidemiol Biomarkers Prev. 2005;14:1619-25.

4. Sato Y, Tsubono Y, Nakaya N, Ogawa K, Kurashima K, Kuriyama S, et al. Fruit and vegetable consumption and risk of colorectal cancer in Japan: The Miyagi Cohort Study. Public Health Nutr. 2005;8:309-14.

5. McCarl M, Harnack L, Limburg PJ, Anderson KE, Folsom AR. Incidence of colorectal cancer in relation to glycemic index and load in a cohort of women. Cancer Epidemiol Biomarkers Prev. 2006; 15:892-6.

6. Park Y, Subar AF, Kipnis V, Thompson FE, Mouw T, Hollenbeck A, et al. Fruit and vegetable intakes and risk of colorectal cancer in the NIH-AARP diet and health study. Am J Epidemiol. 2007;166:170-80.

7. Nomura AM, Wilkens LR, Murphy SP, Hankin JH, Henderson $\mathrm{BE}$, Pike MC, et al. Association of vegetable, fruit, and grain intakes with colorectal cancer: the Multiethnic Cohort Study. Am J Clin Nutr. 2008;88:730-7.

8. Lee SA, Shu XO, Yang G, Li H, Gao YT, Zheng W. Animal origin foods and colorectal cancer risk: a report from the Shanghai Women's Health Study. Nutr Cancer. 2009;61: 194-205.

9. van Duijnhoven FJ, Bueno-De-Mesquita HB, Ferrari P, Jenab M, Boshuizen HC, Ros MM, et al. Fruit, vegetables, and colorectal cancer risk: the European Prospective Investigation into Cancer and Nutrition. Am J Clin Nutr. 2009;89:1441-52.

10. World Cancer Research Fund/American Institute of Cancer Research. Food, Nutrition, Physical Activity, and the Prevention of Cancer: a Global Perspective. Washington DC: American Institute of Cancer Research; 2007.

11. World Cancer Research Fund/American Institute for Cancer Research. Continuous Update Project Report. Food, Nutrition, Physical Activity, and the Prevention of Colorectal Cancer. 2011.

12. Aune D, Lau R, Chan DS, Vieira R, Greenwood DC, Kampman E, et al. Nonlinear reduction in risk for colorectal cancer by fruit and vegetable intake based on meta-analysis of prospective studies. Gastroenterology. 2011;141:106-18.

13. Johnson CM, Wei C, Ensor JE, Smolenski DJ, Amos CI, Levin $\mathrm{B}$, et al. Meta-analyses of colorectal cancer risk factors. Cancer Causes Control. 2013;24:1207-22.

14. Koushik A, Hunter DJ, Spiegelman D, Beeson WL, van den Brandt PA, Buring JE, et al. Fruits, vegetables, and colon cancer risk in a pooled analysis of 14 cohort studies. J Natl Cancer Inst. 2007;99:1471-83.

15. Suzuki S, Kawado M, Hashimoto S, Tokudome S, Yoshimura T, Tamakoshi A; JACC Study Group. Change in food intake 
frequency at five years after baseline in the JACC study. J Epidemiol. 2005;15 Suppl 1:S48-55.

16. Tamakoshi A, Ozasa K, Fujino Y, Suzuki K, Sakata K, Mori M, et al. Cohort profile of the Japan Collaborative Cohort Study at final follow-up. J Epidemiol. 2013;23:227-32.

17. Iso H, Date $C$, Noda H, Yoshimura T, Tamakoshi A; JACC Study Group. Frequency of food intake and estimated nutrient intake among men and women: the JACC Study. J Epidemiol. 2005;15 Suppl 1:S24-42.

18. Date C, Fukui M, Yamamoto A, Wakai K, Ozeki A, Motohashi $\mathrm{Y}$, et al. Reproducibility and validity of a self-administered food frequency questionnaire used in the JACC study. J Epidemiol.
2005;15 Suppl 1:S9-23.

19. Mori M, Sakauchi F, Washio M, Ozasa K, Watanabe Y, Yoshimura T, et al. Survey for incidence of cancer as a measure of outcome in the JACC study. J Epidemiol. 2005;15 Suppl $1: \mathrm{S} 80-5$.

20. Tsubono Y, Otani T, Kobayashi M, Yamamoto S, Sobue T, Tsugane S; JPHC Study Group. No association between fruit or vegetable consumption and the risk of colorectal cancer in Japan. Br J Cancer. 2005;92:1782-4.

21. Curado MP, Edwards B, Shin HR, Storm H, Ferlay J, Heanue M, et al, editors. Cancer Incidence in Five Continents Vol. IX, Lyon: International Agency for Research on Cancer; 2007. 